\title{
Angiotensin II Regulates Th1 T Cell Differentiation Through Angiotensin II Type 1 Receptor-PKA-Mediated Activation of Proteasome
}

\author{
Xian-Yun Qin ${ }^{a} \quad$ Yun-Long Zhang ${ }^{b, c} \quad$ Ya-Fei Chid ${ }^{d}$ Bo Yan ${ }^{a} \quad$ Xiang-Jun Zeng ${ }^{d}$ \\ Hui-Hua Lib,c Ying Liu ${ }^{c}$ \\ aShandong Provincial Key Laboratory of Cardiac Disease Diagnosis and Treatment, Jining Medical \\ University Affiliated Hospital, Jining, b ${ }^{b}$ epartment of Nutrition and Food Hygiene, School of Public \\ Health, Dalian Medical University, Dalian, cDepartment of Cardiology, Institute of Cardiovascular \\ Diseases, First Affiliated Hospital of Dalian Medical University, Dalian, dSchool of Basic Medical \\ Sciences, Capital Medical University, Beijing, China
}

\author{
Key Words \\ Angiotensin II • Th1 differentiation • Jurkat cells • Proteasome $•$ PKA
}

\begin{abstract}
Background/Aims: Naive CD4+ $\mathrm{T}$ cells differentiate into T helper cells (Th1 and Th2) that play an essential role in the cardiovascular diseases. However, the molecular mechanism by which angiotensin II (Ang II) promotes Th1 differentiation remains unclear. The aim of this study was to determine whether the Ang II-induced Th1 differentiation regulated by ubiquitinproteasome system (UPS). Methods: Jurkat cells were treated with Ang II (100 nM) in the presence or absence of different inhibitors. The gene mRNA levels were detected by real-time quantitative PCR analysis. The protein levels were measured by ELISA assay or Western blot analysis, respectively. Results:_Ang II treatment significantly induced a shift from Th0 to Th1 cell differentiation, which was markedly blocked by angiotensin II type 1 receptor (AT1R) inhibitor Losartan (LST). Moreover, Ang II significantly increased the activities and the expression of proteasome catalytic subunits $(\beta 1, \beta 1 i, \beta 2 i$ and $\beta 5 i)$ in a dose- and time-dependent manner. However, Ang II-induced proteasome activities were remarkably abrogated by LST and PKA inhibitor H-89. Mechanistically, Ang II-induced Th1 differentiation was at least in part through proteasome-mediated degradation of IKB $\alpha$ and MKP-1 and activation of STAT1 and NF- $k B$. Conclusions: This study for the first time demonstrates that Ang II activates AT1RPKA-proteasome pathway, which promotes degradation of IKB $\alpha$ and MKP-1 and activation of STAT1 and NF-KB thereby leading to Th1 differentiation. Thus, inhibition of proteasome activation might be a potential therapeutic target for Th1-mediated diseases.
\end{abstract}

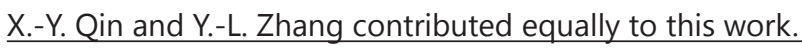




\section{Cellular Physiology Cell Physiol Biochem 2018;45:1366-1376

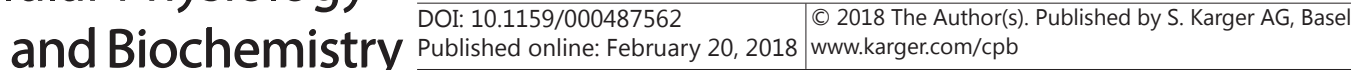 \\ Qin et al.: Proteasome Mediates Ang II-Induced Th Cell Differentiation}

\section{Introduction}

The renin-angiotensin system (RAS) has been demonstrated to play a critical role in the initiation of inflammation that contributes hypertension and cardiac remodeling [1]. Angiotensin II (Ang II) is a multi-functional hormone that has a major role in regulating blood pressure and cardiovascular homoeostasis via angiotensin II receptor type 1 (AT1R) or type 2 (AT2R) [1]. Accumulating evidence indicates that activated effector T lymphocytes exert a key role in the inflammatory response that has been described in cardiovascular disease, such as hypertension, atherosclerosis and heart failure [2]. Initially, The two effector Th subsets are Th1 and Th2. Th1 cells were positively associated with various cardiovascular diseases [3]. Currently, it has been demonstrated that many factors can regulate $\mathrm{T}$ cell differentiation toward the Th1 or the Th2 phenotype including T-box expressed in T cells (T-bet) and (GATA3) T-bet is a'master regulator' of Th1 cell development, while GATA3 is a key T-cell transcription factor to regulate Th2 T-cell differentiation [4], Recently, Ang II-mediated signalling has been reported to play a critical role in Th differentiation [5]. However, the precise mechanism by which Ang II promotes Th1 differentiation remains to be defined.

The ubiquitin-proteasome system (UPS) plays a primary role in the protein quality control by removal of damaged, oxidized, and misfolded proteins [6]. The $26 \mathrm{~S}$ proteasome constitutes major proteolytic machinery in the cell, which consists of a $20 \mathrm{~S}$ core particle and a 19S regulatory particle (also known as PA700) [6]. The 20S core harbors the three catalytic subunits $\beta 1, \beta 2$ and $\beta 5$ in the inner $\beta$-rings. These constitutive subunits can be replaced by the immune-proteasome subunits $\beta 1$ i (LMP2), $\beta 2 \mathrm{i}$ (MECL-1), and $\beta 5 \mathrm{i}$ (LMP7), respectively, in cells in response to pro-inflammatory cytokines such as IFN- $\gamma$ [7], resulting in the alteration of proteolytic activities of proteasome. It is known that $\beta 1 / \beta 1 \mathrm{i}, \beta 2 / \beta 2 \mathrm{i}$ and $\beta 5 / \beta 5 i$ are responsible for caspase-like, trypsin-like, and chymotrypsin-like activities, respectively [6]. Increasing evidence indicates that proteasome complex plays a major role in regulating cell cycle, differentiation and inflammatory response [6]. A well-known example of the ubiquitin-dependent regulation in the immune system is the proteasomedependent processing of peptides in antigen-presenting cells [8]. It is also reported that lipopolysaccharide (LPS) or pro-inflammatory cytokines such as IL-1 can induce activation

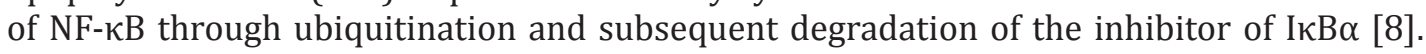
Apart from its role in antigen presentation, immune-proteasomes shape the $\mathrm{T}$ cell repertoire and are responsible for the survival and expansion of T cells [9]. However, the requirement of proteasome activation in Ang II-induced Th cell differentiation has not been explored.

In the present study, we investigated the role of proteasome activation in Ang II-induced Th1/Th2 differentiation in T cells and the underlying mechanism. Our results for the first time demonstrated that Ang II significantly induced a shift from Th0 to Th1 cell differentiation through AT1R/PKA and proteasome activation, which caused both degradation of MKP-1 and

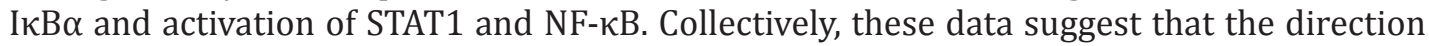
of Th1/Th2 cell differentiation could be controlled by activation of proteasome during Ang II stimulation.

\section{Materials and Methods}

\section{Antibodies and reagents}

Anti-ubiquitin (Ub) was purchased from Santa Cruz Biotechnology (Dallas, TX, USA). Anti- $\beta 1$, anti- $\beta 2$, anti- $\beta 5$, anti- $\beta 1 \mathrm{i}$, anti- $\beta 2 \mathrm{i}$ and anti- $\beta 5 \mathrm{i}$ were obtained from BD Biosciences. Anti-MKP-1, anti-STAT1,anti-

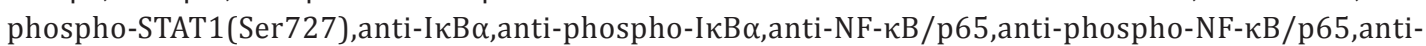
$\beta$-actin and horseradish peroxidase-conjugated goat anti-mouse and anti-rabbit IgG secondary antibody were purchased from Cell Signaling Technology (Beverly, MA). Angiotension II (Ang II) was purchased from Sigma-Aldrich (St Louis, MO, USA). Bortezomib (BTZ) was purchased from Santa Cruz Biotechnology (Santa Cruz, CA). Trypsin, streptomycin, penicillin and fetal calf serum (FCS) were from Hyclone (Logan, UT, USA). Losartan (LST), U0126, wortmannin, SB203580, SP600125 and H-89 were supplied by Calbiochem (La 


\section{Cellular Physiology Cell Physiol Biochem 2018;45:1366-1376 \begin{tabular}{ll|l} 
and Biochemistry Published online: February 20, 2018 & $\begin{array}{l}\text { (c) } 2018 \text { The Author(s). Published by S. Karger AG, Basel } \\
\text { www.karger.com/cpb }\end{array}$ \\
\hline
\end{tabular} \\ Qin et al.: Proteasome Mediates Ang II-Induced Th Cell Differentiation}

Jolla, CA). Other reagents were purchased from Sigma-Aldrich (Louis, MO) and Invitrogen Life Technologies (Carlsbad, CA).

\section{Cell culture and treatment with inhibitors}

Jurkat cells (Clone E6-1), a Th0-like human T lymphoblastoid cell line (ATCC), were grown in suspension at $37^{\circ} \mathrm{C}$ in $5 \% \mathrm{CO}_{2}$, in RPMI 1640 medium supplemented with glutamine ( $\left.2 \mathrm{mM}\right), 10 \%$ fetal bovine serum, and penicillin (100 units $/ \mathrm{ml})$ and streptomycin $(100 \mu \mathrm{g} / \mathrm{ml})$ as described [10]. The cells were passed at a dilution of 1:15 once or twice a week to maintain the maximal density of $2-3 \times 10^{6} \mathrm{cells} / \mathrm{ml}$.

Primary human $\mathrm{T}$ cells $\left(\mathrm{CD} 4^{+} \mathrm{T}\right.$ ) were isolated from anonymous donor blood after apheresis by negative selection (STEMCELL Technologies \#15062) as described previously [11]. T cells were cultured in suspension at $37^{\circ} \mathrm{C}$ in $5 \% \mathrm{CO}_{2}$, RPMI 1640 medium consisting of glutamine ( $\left.2 \mathrm{mM}\right), 5 \%$ fetal bovine serum. All T cells were cultured for 1 to 2 days to maintain the maximal density of $1 \times 10^{6}$ cells $/ \mathrm{ml}$.

To evaluate the involvement of signaling pathways in Ang II-induced cell differentiation, cells were pretreated with BTZ (proteasome inhibitor, $10 \mu \mathrm{M}$ ), LST (AT1 receptor inhibitor, $10 \mu \mathrm{M}$ ), wortmannin (PI3K inhibitor, $200 \mathrm{nM}$ ), U0126 (MEK inhibitor, $10 \mu \mathrm{M}$ ), SB203580 (p38 MAPK inhibitor, $10 \mu \mathrm{M}$ ), SP600125 (JNK inhibitor, $10 \mu \mathrm{M}$ ) and H-89 (PKA inhibitor, $0.5 \mu \mathrm{M}$ ) for 30 min before exposure to Ang II (100 $\mathrm{nM}$ ).

\section{Quantitative real-time PCR analysis}

Total RNA was extracted from cultured cells using TRIzol method (Invitrogen), and $2 \mu \mathrm{g}$ RNA samples were reverse-transcribed to generate first-strand cDNA. Quantitative real-time PCR (qPCR) analysis was performed as described previously [12]. The primer sequences of IFN $\gamma$, IL-2, IL-4, IL-10, T-bet, IFN- $\gamma$, GATA and GAPDH were described as the following: IL-2: 5'- ATGAGACAGCAACCATTGTAGAATTT $-3^{\prime}$ and 5'- CACTTAATTATCAAGTCAGTGTTGAGATGA -3'; IL-4: 5'- ACAGCCTCACAGAGCAGAAGACT $-3^{\prime}$ and 5'- TGTGTTCTTGGAGGCAGCAA -3'; IL-10: 5'- CATCGATTTCTTCCCTGTGAA -3' and 5'- TCTTGGAGCTTATTAAAGGCATTC -3'; T-bet: 5'- GATGTTTGTGGACGTGGTCTTG $-3^{\prime}$ and 5'- CTTTCCACACTGCACCCACTT -3'; IFN- $\gamma:$ 5'- CTAATTATTCGGTAACTGACTTGA -3' and 5'ACAGTTCAGCCATCACTTGGA -3'; GATA: 5'- GGCGCCGTCTTGATACTT -3' and 5'- GTCAGATTGCGTTGCTCGCT -3'; GAPDH: 5' - AGC GAGATCCCTCCAAAATC -3' and 5'- GGCAGAGATGATGACCCTTT -3'.

\section{ELISA assay of IFN $\gamma$ and IL-2 protein levels}

The enzyme-linked immunosorbent assay (ELISA) was performed as described previously [8]. The protein levels of IFN $\gamma$ and IL-2 were measured with an enzyme-linked immunosorbent assay (ELISA) according to the manufacturer's instructions (CUSABIO, America). Briefly, samples and standards were incubated for 2 hours at $37^{\circ} \mathrm{C}$. The biotin-labeled anti- IFN $\gamma$ or IL- 2 antibody was used for detection in a 1:100 dilution and incubated for 1 hour at $37^{\circ} \mathrm{C} .3,3$, 5, 5-tetramethylbenzidine (TMB) substrate was added to each well after labeling with HRP-avidin for 1 hour at $37^{\circ} \mathrm{C}$, and incubated in the dark for $15-30$ minutes at $37^{\circ} \mathrm{C}$. Microtiter plates were read at $450 \mathrm{~nm}$ within 5 minutes after adding stop solution to each well.

\section{Assay for proteasome activity}

The $26 \mathrm{~S}$ proteasome activity was analyzed based on a previously published method [13]. Briefly, cells were harvested and lysed with proteasome lysis buffer $(50 \mathrm{mM}$ Tris- $\mathrm{HCl}, \mathrm{pH}$ 7.8, $20 \mathrm{mM} \mathrm{KCl}, 5 \mathrm{mM} \mathrm{MgCl}, 1$ mM DTT, 1 mM ATP, 10\% glycerol, and 0.04\% Nonidet P-40), followed by incubation on ice for 20 min. Cell lysate with 10-30 $\mu$ g of proteins was incubated with HEPES buffer containing the fluorogenic substrates and incubated at $37^{\circ} \mathrm{C}$ for $1 \mathrm{~h}$. The caspase-like activity was determined with Z-LLE-AMC (45 $\left.\mu \mathrm{M}\right)$, trypsin-like activity with Ac-RLR-AMC $(40 \mu \mathrm{M})$, and chymotrypsin-like activity with Suc-LLVY-AMC $(18 \mu \mathrm{M})$ as substrates in the absence or presence of a proteasome inhibitor, MG-132 (20 $\mu \mathrm{M})$ for chymotrypsinlike and caspaselike activities, or epoxomycin $(5 \mu \mathrm{M})$ for trypsin-like activity. The fluorescence intensity was measured with the excitation at $380 \mathrm{~nm}$ and emission at $460 \mathrm{~nm}$.

\section{Western blot analysis}

Western blot analysis was performed as previously described [8]. Cells were lysed with lysis buffer (20 mM Tris (pH7.5), 1 mM EDTA, 150 mM NaCl, 1 mM EGTA, 1 mM $\beta$-glycerophosphate, 1\%Triton X-100, 2.5 $\mathrm{mM}$ sodium pyrophosphate, $1 \mathrm{mM} \mathrm{Na3VO} 4,4 \mu \mathrm{g} / \mathrm{ml}$ aprotinin, $4 \mu \mathrm{g} / \mathrm{ml}$ leupeptin, $4 \mu \mathrm{g} / \mathrm{ml}$ pepstatin, and 1 $\mathrm{mM}$ PMSF). No phosphatase inhibitors were included in the lysis buffer. 50-60 $\mu$ g protein from each sample 
were separated by SDS-PAGE, transferred to nitrocellulose membranes, and probed with primary antibodies against $\beta 1$ (1:500), $\beta 2$ (1:500), $\beta 5$ (1:500), $\beta 1 \mathrm{i}$ (1:500), $\beta 2 \mathrm{i}$ (1:500), $\beta 5 \mathrm{i}$ (1:500), total- and phospho-STAT1

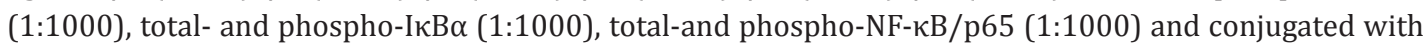
horseradish peroxidase-conjugated secondary antibodies, For the phospho-specific protein, we normalized the signal to the amount of total target protein and $\beta$-actin.

Analysis of poly-ubiquitinated proteins

Cells were lysed with lysis buffer as above, Jurkat cells were treated with $100 \mathrm{nM}$ of Ang II for different time points $(0,4,8$ and $24 \mathrm{~h})$, and were further lysed with lysis buffer as above. Poly-ubiquitinated proteins were detected by Western blot analysis as described previously [8]. Briefly, $60 \mu \mathrm{g}$ proteins from each time point were separated by SDS-PAGE and probed with primary antibodies against Ub $(1: 1000)$ and $\beta$-actin.

\section{Statistical analysis}

Data are expressed as mean \pm SEM. One-way ANOVA followed by Least-Significant-Difference test was conducted to compare three or more groups using SPSS version 12.0 (SPSS Inc., Chicago, IL). P< 0.05 was considered statistically significant.

\section{Results}

Ang II predominantly induces Th1 differentiation through AT1 receptor

To determine the causative role of Ang II in regulating $\mathrm{T}$ lymphocyte differentiation, we measured the expression of Th1 markers (IFN- $\gamma$ and IL2) and Th2 markers (IL-4 and IL-10) in Jurkat cells and normal primary human $\mathrm{T}$ cells $\left(\mathrm{CD} 4^{+} \mathrm{T}\right)$. qPCR analysis revealed that the expression levels of IL-2, IFN- $\gamma$, Il-4 and IL10 were similar, indicating that both Jurkat cells and primary human $\mathrm{T}$ cells are Th0 cells (Fig. 1A and 1B). Moreover, treatment with Ang II (100 nM) significantly up-regulated the expression of IFN- $\gamma$ (10-fold) and IL-2 (18-fold) but slightly increased the expression of IL-4 (3.5-fold) and IL-10 (1.5-fold) compared with control (Fig. 1C). Since T-bet and GATA3 are the key regulators for Th1 and Th2 cell differentiation, respectively [4], we then detected the expression levels of T-bet and GATA3 mRNA in Jurkat cells. After Ang II treatment, the expression of T-bet mRNA was markedly increased by 38-fold, whereas the expression of GATA3 mRNA was only increased by 1.6-fold as compared with control (Fig. 1D-E).

Previous study indicates that $\mathrm{T}$ lymphocytes mainly express AT1R and produce Ang II [14], we then examined whether AT1R participates in the Th1 differentiation. Jurkat cells were pretreated with AT1R blocker losartan

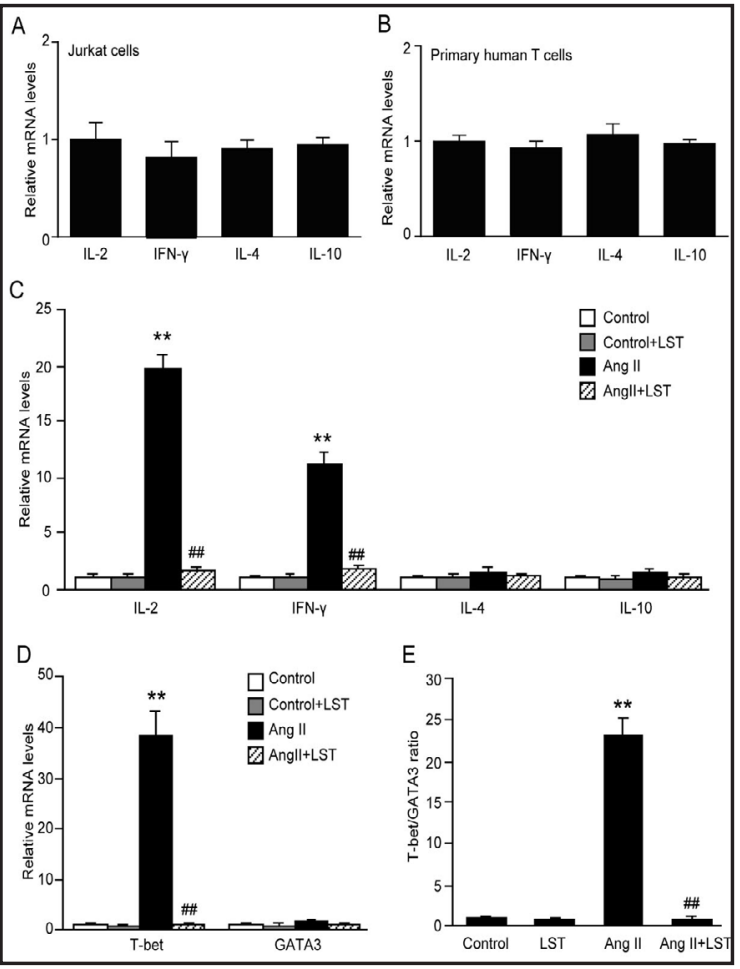

Fig. 1. Ang II-induced Th1 differentiation is through AT1R. The expression of Th1 markers (IFN- $\gamma$, IL-2) and Th2 markers (IL-4 and IL-10) in Jurkat cells (A) and (B) primary human $\mathrm{T}$ cells were analyzed by qPCR analysis. (C) Jurkat cells were pretreated with $10 \mu \mathrm{M}$ of losartan (LST, an AT1R inhibitor) for $30 \mathrm{~min}$ and then stimulated with $100 \mathrm{nM}$ of Ang II for $24 \mathrm{~h}$. The mRNA expression of IFN- $\gamma$, IL-2, IL-4 and IL-10 was measured by qPCR analysis. (D) The mRNA expression of T-bet and GATA3 was measured by qPCR analysis. (E) The ratio of T-bet and GATA3 was calculated in each grioup. Data are expressed as mean \pm SEM ( $n=5$ per group). " $(\mathrm{p}<0.01)$ versus control; $\#$ ( $p<0.01)$ versus Ang II. 
Fig. 2. Ang II enhances proteasome activities. (A) Jurkat cells were treated with various doses of Ang II $(25,50$ and $100 \mathrm{nM}$ ) for $24 \mathrm{~h}$. Proteasome activities of chymotrypsin-like, caspase-like, and trypsin-like were measured by using fluorogenic substrates. (B). Cells were treated with $100 \mathrm{nM}$ of Ang II for different time points (4, 8 and 24 h). Proteasome activities were measured as in A. (C) Cells were pretreated with bortezomib (BTZ, $10 \mu \mathrm{M}$ ) for $30 \mathrm{~min}$ and then stimulated with $100 \mathrm{nM}$ of Ang II for additional $24 \mathrm{~h}$. Proteasome activities were measured as in A. Data are expressed as mean \pm SEM ( $\mathrm{n}=5$ per group) ${ }^{*}(\mathrm{p}<0.01),{ }^{\#}(\mathrm{p}<0.05)$ versus control; ${ }^{\&}(\mathrm{p}<0.01)$ versus Ang II.

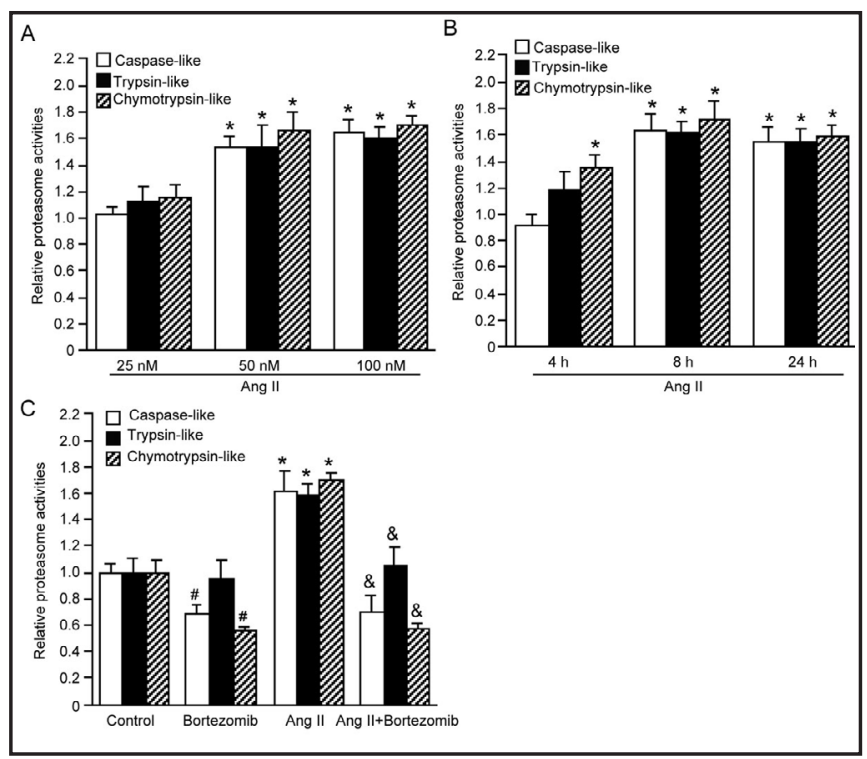

Fig. 3. Ang II decreases the levels of poly-ubiquitinated proteins and increases the protein levels of proteasome catalytic subunits. (A) Jurkat cells were treated with $100 \mathrm{nM}$ of Ang II for different time points $(0,4,8$ and $24 \mathrm{~h})$. Poly-ubiquitinated proteins were detected by Western blot analysis. (B) Quantification of relative poly-ubiquitinated proteins for each group. (C) Jurkat cells were treated with $100 \mathrm{nM}$ of Ang II for different time points $(0$, 4, 8 and $24 \mathrm{~h}$ ). The protein levels of constitutive catalytic subunits $(\beta 1, \beta 2$ and $\beta 5)$ were detected by Western blot analysis (top). Quantification of relative protein intensity was shown (bottom). (D) The quantification of the protein levels of proteasome subunits ( $\beta 1 \mathrm{i}, \beta 2 \mathrm{i}$ and $\beta 5 \mathrm{i}$ ) was performed. Data are expressed as mean \pm SEM $(\mathrm{n}=5$

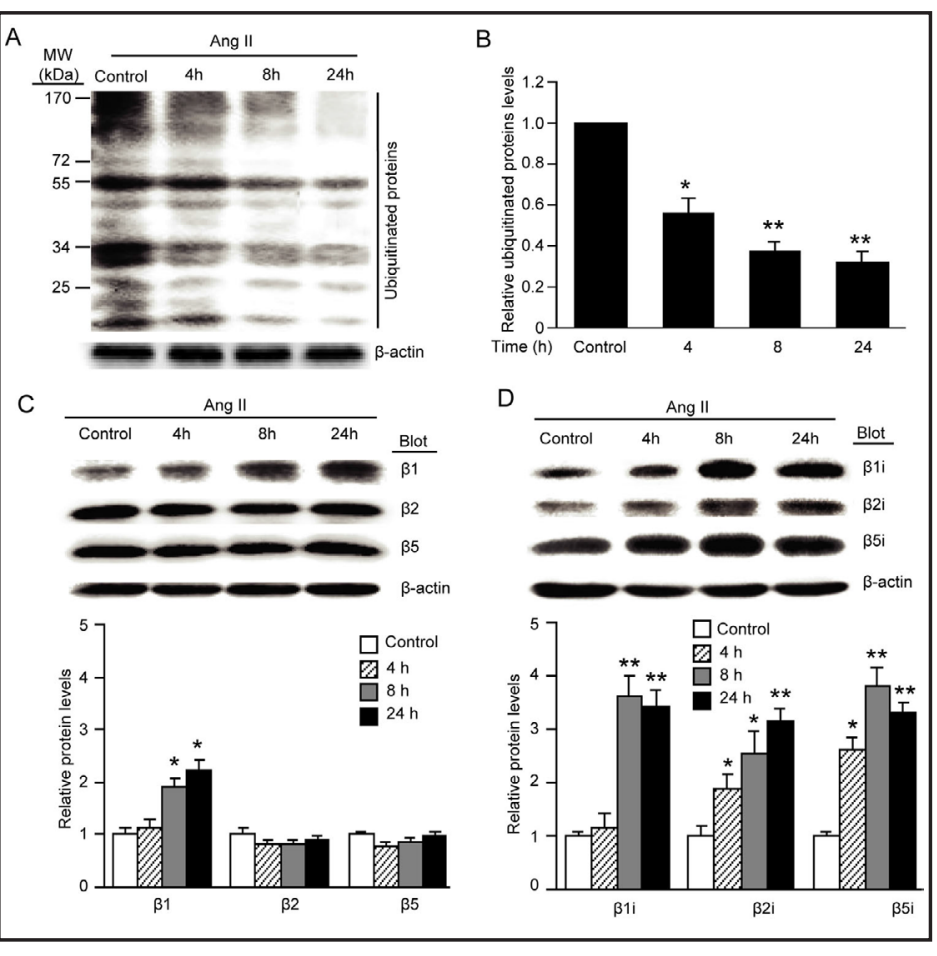
per group). ${ }^{*}(\mathrm{p}<0.05),{ }^{* *}(\mathrm{p}<0.01)$ versus $0 \mathrm{~h}$.

(LST) for $30 \mathrm{~min}$ and then stimulated with Ang II for $24 \mathrm{~h}$. As shown in Fig. 1C-E, LST completely abolished Ang II-induced expression of IFN- $\gamma$, IL-2 and T-bet (markers for Th1 differentiation), whereas LST had no significant effect on IL-4, IL-10 and GATA3 (markers for Th2 differentiation). Together, these data suggest that Ang II preferentially stimulates Th1 rather than Th2 differentiation via AT1R.

Ang II increases proteasome activities but reduces the pool of poly-ubiquitinated proteins

To determine the role of the proteasome in $\mathrm{T}$ lymphocyte differentiation, we first examined the effect of Ang II on proteasome activation. Jurkat cells were treated with Ang 


\section{Cellular Physiology Cell Physiol Biochem 2018:45:1366-1376

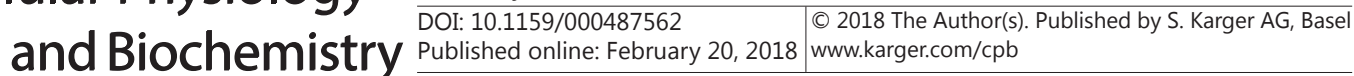

Fig. 4. Ang II increases proteasome activities through AT1R-PKA Signaling Pathway. Jurkat cells were pretreated with different signalling inhibitors, including (A) LST (an AT1R inhibitor, $10 \mu \mathrm{M}$ ), (B) H-89 (a PKA-specific inhibitor, $0.5 \mu \mathrm{M})$, (C) Wortmannin (a PI3K inhibitor, 200 nM), (D) U0126 (a ERK inhibitor, $10 \mu \mathrm{M}$ ), (E) SB203580 (a p38 MAPK inhibitor, $10 \mu \mathrm{M})$,), and (F) SP600125 (a JNK inhibitor, $10 \mu \mathrm{M}$ ) for $30 \mathrm{~min}$ and then treated with Ang II (100 nM) for additional $24 \mathrm{~h}$. Proteasome activities of chymotrypsin-like, caspase-like, and trypsin-like were measured by using fluorogenic substrates. Data are expressed as mean \pm SEM $(n=5$ per group). ${ }^{*}(p<0.01)$ versus control; ${ }^{*}(\mathrm{p}<0.05)$ versus Ang II.
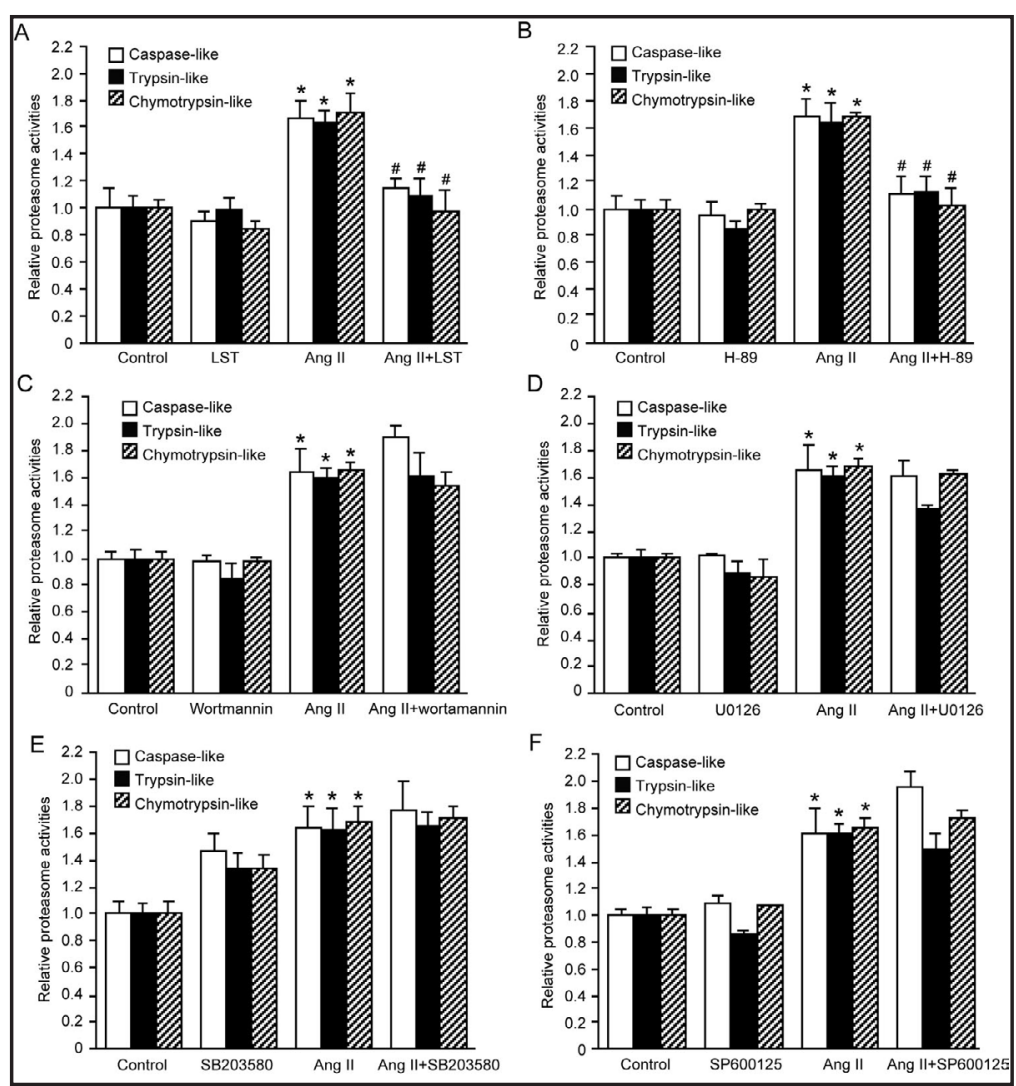

II at different doses (25, 50 and $100 \mathrm{nM})$ and at different time points (4, 8 and $24 \mathrm{~h})$. The proteasome activities, including caspase-like, trypsin-like, and chymotrypsin-like activities were measured using fluorescent-labeled peptides. As shown in Fig. 2A, Ang II treatment markedly increased proteasome caspase-like, trypsin-like and chymotrypsin-like activities in a dose-dependent manner. Ang II also enhanced proteasome activities in a time-dependent manner (Fig. 2B). Moreover, this induction was markedly attenuated by a specific proteasome inhibitor bortezomib (BTZ) (Fig. 2C). These results suggest that Ang II-induced activities were specifically associated with the proteasome.

\section{Ang II induces the expression of proteasome protein subunits}

Proteasome activation has been known to increase the degradation of poly-ubiquitinated proteins. We next examined the levels of poly-ubiquitinated proteins by Western blot analysis in Jurkat cells. Ang II treatment for 0-24 h markedly decreased the levels of polyubiquitinated proteins in a time-dependent manner (Fig. 3A and 3B), indicating that Ang II can enhance the turnover of ubiquitinated proteins in Jurkat cells.

To determine the effect of Ang II in the expression of catalytic subunits, we treated Jurkat cells with Ang II (100 nM) at different time points (4, 8 and $24 \mathrm{~h})$. The protein levels of the constitutive and inducible proteasome catalytic subunits (including $\beta 1, \beta 2, \beta 5, \beta 1 \mathrm{i}, \beta 2 \mathrm{i}$ and $\beta 5 \mathrm{i}$ ) were detected by Western blot analysis. Ang II treatment significantly increased the protein levels of constitutive subunit $(\beta 1)$ and immuno-subunits $(\beta 1 i, \beta 2 i$ and $\beta 5 i)$ but did not affect other constitutive subunits ( $\beta 2$ and $\beta 5$ ) (Fig. 3C and D), indicating that Ang II-induced increase of proteasome activity is mainly mediated by incread expression of proteasome subunits $\beta 1 / \beta 1 \mathrm{i}, \beta 2 \mathrm{i}$ and $\beta 5 \mathrm{i}$ in Jurkat cells.

Ang II stimulates proteasome activation through AT1R-PKA signaling pathway

To further elucidate the signalling pathway whereby Ang II-induced proteasome activation, Jurkat cells were pretreated with different signalling inhibitors, including losartan 
Fig. 5. Bortezomib attenuates Ang IIinduced Th1 differentiation. (A) Primary human T cells and (B) Jurkat cells were pretreated with bortezomib (BTZ, 10 $\mu \mathrm{M}$ ) for $30 \mathrm{~min}$ and then stimulated with $100 \mathrm{nM}$ of Ang II for additional $24 \mathrm{~h}$. The mRNA expression of IFN- $\gamma$, IL-2, IL-4 and IL-10 was measured by qPCR analysis. (C) Jurkat cells were pretreated with 10 $\mu \mathrm{M}$ of losartan (LST, an AT1R inhibitor) for $30 \mathrm{~min}$ and then stimulated with 100 $n M$ of Ang II for $24 \mathrm{~h}$. The mRNA expression of IFN- $\gamma$, IL-2, IL-4 and IL-10 was measured by qPCR analysis. (D) The ratio of T-bet and GATA3 was calculated in each grioup. Data are expressed as mean \pm SEM ( $\mathrm{n}=5$ per group). ${ }^{* *}(\mathrm{p}<0.01)$ versus control; $\#$ ( $\mathrm{p}<0.01)$ versus Ang II.

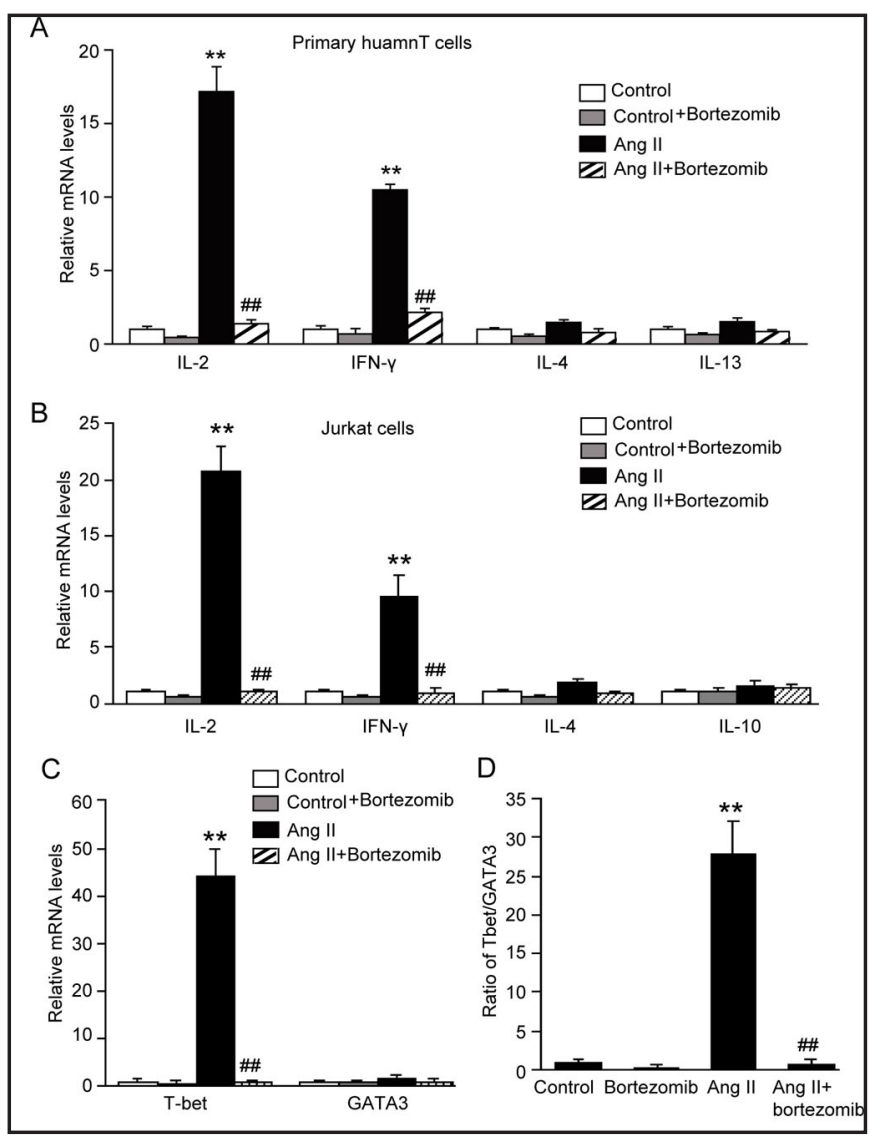

(LST, an AT1R inhibitor), H-89 (a PKA-specific inhibitor), wortmannin (a PI3K inhibitor), U0126 (a MEK inhibitor), SB203580 (a p38 MAPK inhibitor) and SP600125 (a JNK inhibitor). As shown in Fig. 4A-F, Ang II-induced increase in proteasome activities (including caspaselike, trypsin-Like and chymotrypsin-like activities) were markedly attenuated by LST or $\mathrm{H}-89$, respectively. In contrast, other inhibitors, including wortmannin, U0126, SB203580 and SP600125 had no effect. These results indicate that AT1R-PKA signalling pathway mediates Ang II-induced activation of the proteasome.

\section{Proteasome inhibitor bortezomib suppresses Ang II-induced Th1 differentiation}

To further determine whether proteasome activation mediates Ang II-induced Th1 differentiation, primary human T cells were pretreated with proteasome inhibitor bortezomib (BTZ) for $30 \mathrm{~min}$ and then stimulated with Ang II for additional $24 \mathrm{~h}$. Ang II treatment resulted in a significant increase in the expressions of Th1 markers (IFN- $\gamma$, IL-2) but not Th2 markers (IL4, IL10) (Fig. 5A). Also, we tested the effect of Ang II on Th1 markers and Th2 markers in Jurkat cells and we further treated the Jurkat cells with BTZ. Consistent with the findings observed in primary human T cells, Ang II-stimulated upregulation of Th1 markers (IFN- $\gamma$, IL-2 and T-bet) but not Th2 markers (IL4, IL10 and GATA3). BTZ treatment markedly attenuated Ang II-induced activities, suggesting Ang II were specifically associated with the proteasome (Fig. 5B-D).

Bortezomib inhibits Ang II-induced the degradation of MKP-1 and IKB $\alpha$ and activation of STAT1 and NF- $\kappa B$

It is well documented that STAT1 and NF- $\kappa B$ signalling pathways play critical roles in Th1 differentiation and activation [15]. MKP-1 and I $\mathrm{B} \alpha \alpha$ can negatively regulate activation of STAT1 and NF- $\kappa \mathrm{B}$, respectively, which are reported to be degradated by the proteasome [16]. To determine whether inhibition of proteasome reversed MKP-1 and IкB $\alpha$ protein 


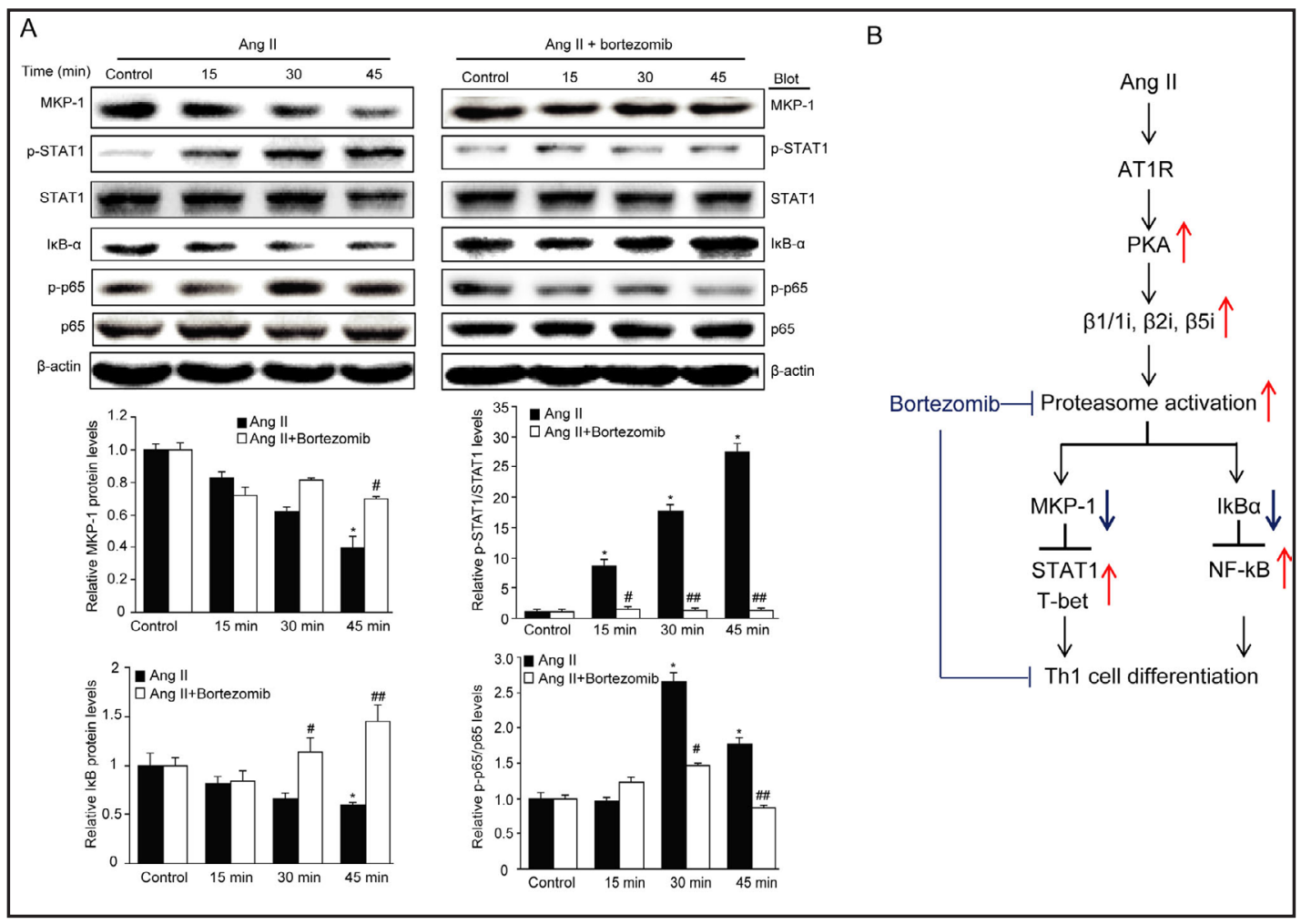

Fig. 6. Effects of Ang II on MKP-1/STAT1 and I $\mathrm{B} \alpha / \mathrm{NF}-\kappa \mathrm{B}$ signaling pathways. (A) Jurkat cells were pretreated with bortezomib (BTZ, $10 \mu \mathrm{M}$ ) for $30 \mathrm{~min}$ and then stimulated with $100 \mathrm{nM}$ of Ang II for different time points $(0,15,30$ and $45 \mathrm{~min})$. The protein levels of MKP-1, IкB $\alpha$, STAT1, p65, p-STAT1 and p-p65 were detected by Western blot analysis (top). Quantification of relative protein intensity was shown (bottom). Data are expressed as mean \pm SEM ( $n=3$ per group). ${ }^{*}(p<0.05)$ versus control; ${ }^{\#}(p<0.05),{ }^{\# \#(}(p<0.01)$ versus Ang II. (B) Proposed mechanism for Ang II-induced Th1 differentiation through AT1R-PKA signaling and

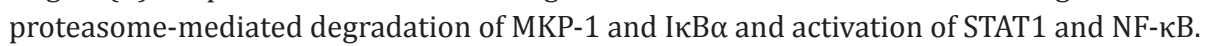

levels, Jurkat cells were pretreated with BTZ for $30 \mathrm{~min}$ and then stimulated with Ang II for 0-45 min. Ang II treatment significantly decreased the levels of MKP-1 and IкB $\alpha$ proteins but increased the levels of phosphorylated STAT1 and p65/NF- $\mathrm{BB}$ at different time points (Fig. 6A). Importantly, BTZ treatment markedly reversed these effects. These data suggest that

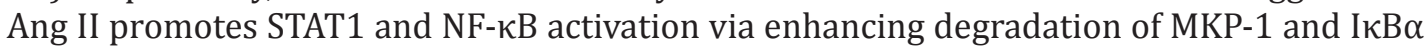
by the proteasome.

\section{Discussion}

In this study, we explored the role of proteasome activation in Ang II-induced $\mathrm{T}$ cell differentiation in Jurkat cells and primary human T cells. The present study demonstrated that Ang II induces the expression of proteasome protein subunits and predominantly stimulates Th1 differentiation. This effect of Ang II in proteasome activities is associated with activation of AT1R/PKA signaling pathway, which in turn promote the degradation of

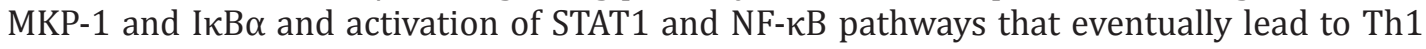
cell differentiation. Also, inhibition of proteasome activation or AT1R markedly attenuated these effects (Fig. 6B). Hence this study uncovered new potential mechanisms exhibiting regulatory effect of UPS in Ang II induced Th1 cell differentiation.

The UPS is the main mechanism of ubiquitin-dependent degradation of intracellular proteins involved in the regulation of cell cycle, apoptosis, signal transduction and antigen presentation [17]. Importantly, many studies have demonstrated that proteasome activation plays a critical role in the development of various cardiovascular diseases [18]. Now it is 


\section{Cellular Physiology Cell Physiol Biochem 2018;45:1366-1376 \\ and Biochemistry $\begin{gathered}\text { DOI: 10.1159/000487562 } \\ \text { Published online: February 20, } 2018\end{gathered} \begin{aligned} & \text { O } 2018 \text { The Author(s). Published by S. Karger AG, Basel } \\ & \text { wwwer.com/cpb }\end{aligned}$ \\ Qin et al.: Proteasome Mediates Ang II-Induced Th Cell Differentiation}

known that the functions and activities of the 26S proteasome are regulated by multiple mechanisms. For example, post-translational modifications including phosphorylation and glycosylation have been reported to regulate the proteasome activities [17]. Recently, several factors, including reactive oxygen species (ROS), mechanical stress, and isoproterenol, were reported to promote catalytic subunit expression to generate immunoproteasomes, which have altered enzymatic activities for their substrates [17]. Ang II is known to bind its receptors to activate several signalling pathways, including MAPKs (ERK, JNK and p38 MAPK), PI3K/AKT, and PKA, which play important roles in mediating Ang II-induced cellular responses, such as cell growth, differentiation, reorganization of the cytoskeleton, and activation of a variety of protein kinases [1]. In this study, our data indicate that Ang II also enhanced proteasome activation (Fig. 2-4), and this effect was completely blocked AT1R or PKA inhibitor (Fig. 4). Hence, AT1R/PKA pathway is involved in Ang II-induced activation of the proteasome in T cells.

Naive $\mathrm{CD} 4^{+} \mathrm{T}$ cells can differentiate into different Th cell lineages that are essential for efficient immune responses against different types of pathogens $[4,10]$. Many factors are known to regulate Th1 and Th2 differentiation, especially renin-angiotensin system (RAS). A growing body of evidence suggests that anti-CD3/CD28 treatment also induces Th1 differentiation reflected by upregulation of IL-2, IFN- $\alpha$ and NF-kB activity in Jurkat cells or in human $\mathrm{CD}^{+} \mathrm{T}$ cells $[19,20]$. Many factors are known to regulate Th1 and Th2 differentiation, including renin-angiotensin system (RAS).Ang II, a major effector of RAS, plays a critical role in this process. For example, splenocytes from high Ang II-treated Apo E knockout mice produce elevated levels of IFN- $\gamma$ (a marker for Th1 cells) and decreased levels of IL4 and IL10 (markers for Th2 cells), and this effect was blocked by pretreatment with AT1R blocker olmesartan [21]. Co-stimulation of T cells via B7 ligands was found essential for the development of Ang II-induced hypertension [22]. Moreover, Ang II can enhance Th1 cell activation that speeds up atherogenesis [23]. In addition to the classic circulating RAS, all RAS components have been identified in the heart, which may mediate autocrine, paracrine, and intracrine effects [24]. Interestingly, endogenous Ang II production is increased in the ischemic and hypertrophic myocardium or in the $2 \mathrm{~K} 1 \mathrm{C}$ hypertension model in $\mathrm{ApoE}^{-/-}$mice, and participate in cardiovascular events including atherosclerosis [23, 25]. Endogenous Ang II induces atherosclerotic plaque vulnerability and elicits a Th1 response in $\mathrm{ApoE}^{-/-}$mice, suggesting Ang II plays a critical role in regulating Th1 differentiation [23]. In this study, Ang II stimulates Th1 differentiation via enhancing proteasome activity and proteasome inhibitor bortezomib significantly inhibited Ang II-induced Th1 differentiation (Fig. 5).

Recently, several transcription factors that control Th1/Th2 cell differentiation were identified $[26,27]$. Of these, T-bet and GATA3 are found to be the key regulators for Th1 and Th2 cell differentiation [28]. Yang et al. reported that STAT1/4 can bind T-bet enhancer and regulate T-bet expression [15]. Also, MKP-1 is a dual specificity nuclear phosphatase responsible for dephosphorylation at both serine/threonine and tyrosine residues and is involved in the dephosphorylation of IFN $\gamma$-activated nuclear STAT1 [16, 29].Interestingly, MKP-1 is also involved in dephosphorylation of STAT1 induced by Ang II, but not in the inactivation of STAT3 activated by IL-6 [24]. Furthermore, NF- $\mathrm{KB}$ is regulated by the inhibitor

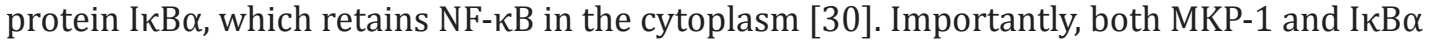
protein levels were regulated by ubiquitin-mediated proteasomal degradation [16]. The present results demonstrated that Ang II markedly promoted Th1 cell differentiation, and down-regulated protein levels of MKP- 1 and I $\kappa$ B $\alpha$ resulting in activation of STAT1 and NF- $\kappa B$ pathways. Importantly, inhibition of proteasome by BTZ markedly reversed these effects (Fig. 6A), suggesting Ang II stimulates Th1 cell differentiation via activation of the proteasome in Jurkat cells.

\section{Conclusion}

Our study demonstrates for the first time that Ang II activates AT1R/PKA signalling pathway, which in turn to increase the catalytic subunit expression and activity of proteasome, 


\section{Cellular Physiology Cell Physiol Biochem 2018;45:1366-1376 \begin{tabular}{ll|l} 
and Biochemistry & $\begin{array}{l}\text { DOI: 10.1159/000487562 } \\
\text { Published online: February 20, } 2018\end{array}$ & $\begin{array}{l}\text { 2018 The Author(s). Published by S. Karger AG, Basel } \\
\text { wwwer.com/cpb }\end{array}$ \\
\cline { 2 - 3 }
\end{tabular} \\ Qin et al.: Proteasome Mediates Ang II-Induced Th Cell Differentiation}

thereby promoting Th1 cell differentiation. In contrast, this process was interrupted largely by use of proteasome inhibitor (Fig. 6B). These results provide new insights into the function of proteasome in Th cell differentiation in response to Ang II stress, and inhibition of proteasome might be a novel therapeutic target for treatment of Th1-mediated diseases.

\section{Acknowledgements}

This work was supported by grants from the National Natural Science Foundation of China (81330003, 81630009, 31571170 to HHL; 81400247 to YL), and Chang Jiang Scholar Program of China (T2011160 to HHL).

\section{Disclosure Statement}

No conflict of interests exists.

\section{References}

1 Mehta PK, Griendling KK: Angiotensin II cell signaling: physiological and pathological effects in the cardiovascular system. Am J Physiol Cell Physiol 2007;292:C82-97.

-2 Harrison DG, Guzik TJ, Lob HE, Madhur MS, Marvar PJ, Thabet SR, Vinh A, Weyand CM: Inflammation, immunity, and hypertension. Hypertension 2011;57:132-140.

-3 Schiffrin EL: Immune mechanisms in hypertension and vascular injury. Clin Sci (Lond) 2014;126:267-274.

4 Yagi R, Zhu J, Paul WE: An updated view on transcription factor GATA3-mediated regulation of Th1 and Th2 cell differentiation. Int Immunol 2011;23:415-420.

5 Ohwada K, Watanabe K, Okuyama K, Ohkawara Y, Sugaya T, Takayanagi M, Ohno I: The involvement of type 1a angiotensin II receptors in the regulation of airway inflammation in a murine model of allergic asthma. Clin Exp Allergy 2007;37:1720-1727.

6 Nandi D, Tahiliani P, Kumar A, Chandu D: The ubiquitin-proteasome system. J Biosci 2006;31:137-155.

7 Groettrup M, Khan S, Schwarz K, Schmidtke G: Interferon-gamma inducible exchanges of 20S proteasome active site subunits: why? Biochimie 2001;83:367-372.

8 Chen C, Meng Y, Wang L, Wang HX, Tian C, Pang GD, Li HH, Du J: Ubiquitin-activating enzyme E1 inhibitor PYR41 attenuates angiotensin II-induced activation of dendritic cells via the IkappaBa/NF-kappaB and MKP1/ERK/STAT1 pathways. Immunology 2014;142:307-319.

-9 Chen W, Norbury CC, Cho Y, Yewdell JW, Bennink JR: Immunoproteasomes shape immunodominance hierarchies of antiviral CD8(+) T cells at the levels of T cell repertoire and presentation of viral antigens. J Exp Med 2001;193:1319-1326.

10 Liu Y, Zhao X, Zhong Y, Meng K, Yu K, Shi H, Wu B, Tony H, Zhu J, Zhu R, Peng Y, Mao Y, Cheng P, Mao X, Zeng Q: Heme oxygenase-1 restores impaired GARPCD4(+)CD25(+) regulatory T cells from patients with acute coronary syndrome by upregulating LAP and GARP expression on activated T lymphocytes. Cell Physiol Biochem 2015;35:553-570.

-11 Roybal KT, Williams JZ, Morsut L, Rupp LJ, Kolinko I, Choe JH, Walker WJ, McNally KA, Lim WA: Engineering T Cells with Customized Therapeutic Response Programs Using Synthetic Notch Receptors. Cell 2016;167:419-432 e416.

12 Zhang JS, Zhang YL, Wang HX, Xia YL, Wang L, Jiang YN, Li HH, Liu Y: Identification of genes related to the early stage of Angiotensin II-induced acute renal injury by microarray and integrated gene network analysis. Cell Physiol Biochem 2014;34:1137-1151.

13 Vilchez D, Boyer L, Morantte I, Lutz M, Merkwirth C, Joyce D, Spencer B, Page L, Masliah E, Berggren WT, Gage FH, Dillin A: Increased proteasome activity in human embryonic stem cells is regulated by PSMD11 Nature 2012;489:304-308. 


\section{Cellular Physiology Cell Physiol Biochem 2018;45:1366-1376 \begin{tabular}{l|l|l|l|l} 
DOI: 10.1159/000487562 & O 2018 The Author(s). Published by S. Karger AG, Basel \\
www.karger.com/cpb
\end{tabular} \\ Qin et al.: Proteasome Mediates Ang II-Induced Th Cell Differentiation}

14 Hoch NE, Guzik TJ, Chen W, Deans T, Maalouf SA, Gratze P, Weyand C, Harrison DG: Regulation of T-cell function by endogenously produced angiotensin II. Am J Physiol Regul Integr Comp Physiol 2009;296:R208-216.

15 Yang Y, Ochando JC, Bromberg JS, Ding Y: Identification of a distant T-bet enhancer responsive to IL-12/ Stat4 and IFNgamma/Stat1 signals. Blood 2007;110:2494-2500.

-16 Ho HJ, Huang DY, Ho FM, Lee LT, Lin WW: Inhibition of lipopolysaccharide-induced inducible nitric oxide synthase expression by endoplasmic reticulum stress. Cell Signal 2012;24:2166-2178.

$>17$ Angeles A, Fung G, Luo H: Immune and non-immune functions of the immunoproteasome. Front Biosci (Landmark Ed) 2012;17:1904-1916.

18 Pagan J, Seto T, Pagano M, Cittadini A: Role of the ubiquitin proteasome system in the heart. Circ Res 2013;112:1046-1058.

19 Tomkowicz B, Walsh E, Cotty A, Verona R, Sabins N, Kaplan F, Santulli-Marotto S, Chin CN, Mooney J, Lingham RB, Naso M, McCabe T: TIM-3 Suppresses Anti-CD3/CD28-Induced TCR Activation and IL-2 Expression through the NFAT Signaling Pathway. PLoS One 2015;10:e0140694.

20 Williams TM, Moolten DM, Makni H, Kim HW, Kant JA, Kamoun M: CD28-stimulated IL-2 gene expression in Jurkat T cells occurs in part transcriptionally and is cyclosporine-A sensitive. J Immunol 1992;148:26092616.

21 Palmer DC, Restifo NP: Suppressors of cytokine signaling (SOCS) in T cell differentiation, maturation, and function. Trends Immunol 2009;30:592-602.

22 Vinh A, Chen W, Blinder Y, Weiss D, Taylor WR, Goronzy JJ, Weyand CM, Harrison DG, Guzik TJ: Inhibition and genetic ablation of the B7/CD28 T-cell costimulation axis prevents experimental hypertension. Circulation 2010;122:2529-2537.

23 Mazzolai L, Duchosal MA, Korber M, Bouzourene K, Aubert JF, Hao H, Vallet V, Brunner HR, Nussberger J, Gabbiani G, Hayoz D: Endogenous angiotensin II induces atherosclerotic plaque vulnerability and elicits a Th1 response in ApoE-/- mice. Hypertension 2004;44:277-282.

24 Bader M, Peters J, Baltatu O, Muller DN, Luft FC, Ganten D: Tissue renin-angiotensin systems: new insights from experimental animal models in hypertension research. J Mol Med (Berl) 2001;79:76-102.

-25 Mackins CJ, Kano S, Seyedi N, Schafer U, Reid AC, Machida T, Silver RB, Levi R: Cardiac mast cell-derived renin promotes local angiotensin formation, norepinephrine release, and arrhythmias in ischemia/ reperfusion. J Clin Invest 2006;116:1063-1070.

26 Xu X, Gao X, Zhao X, Liao Y, Ji W, Li Q, Li J: PU.1-Silenced Dendritic Cells Induce Mixed Chimerism and Alleviate Intestinal Transplant Rejection in Rats via a Th1 to Th2 Shift. Cell Physiol Biochem 2016;38:220228.

27 Wang L, Wu G, Qin X, Ma Q Zhou Y, Liu S, Tan Y: Expression of Nodal on Bronchial Epithelial Cells Influenced by Lung Microbes Through DNA Methylation Modulates the Differentiation of T-Helper Cells. Cell Physiol Biochem 2015;37:2012-2022.

28 Qiao SK, Ren HY, Shi YJ, Liu W: Allogeneic Compact Bone-Derived Mesenchymal Stem Cell Transplantation Attenuates the Severity of Idiopathic Pneumonia Syndrome in a Murine Bone Marrow Transplantation Model. Cell Physiol Biochem 2016;40:1656-1669.

29 Liu D, Scafidi J, Prada AE, Zahedi K, Davis AE, 3rd: Nuclear phosphatases and the proteasome in suppression of STAT1 activity in hepatocytes. Biochem Biophys Res Commun 2002;299:574-580.

30 Hinz M, Scheidereit C: The IkappaB kinase complex in NF-kappaB regulation and beyond. EMBO Rep 2014;15:46-61. 